\title{
Crash Modification Factors for Dynamic Speed Feedback Signs on Rural Curves
}

\author{
Shauna L. Hallmark ${ }^{*}$, Yu Qiu ${ }^{2}$, Neal Hawkins ${ }^{1}$, Omar Smadi ${ }^{1}$ \\ ${ }^{1}$ Center for Transportation Research and Education, lowa State University, Ames, lowa, USA \\ ${ }^{2}$ Plymouth Rock Assurance Inc., Boston, MA, USA \\ Email: shallmar@iastate.edu, hawkins@iastate.edu, smadi@iastate.edu
}

Received 22 October 2014; revised 18 November 2014; accepted 2 December 2014

Academic Editor: Mingxin Li, University of Delaware, USA

Copyright (C) 2015 by authors and Scientific Research Publishing Inc.

This work is licensed under the Creative Commons Attribution International License (CC BY). http://creativecommons.org/licenses/by/4.0/

(c) (i) Open Access

\begin{abstract}
A large number of crashes occur on curves even though they account for only a small percentage of a system's mileage. Excessive speed has been identified as a primary factor in both lane departure and curve-related crashes. A number of countermeasures have been proposed to reduce driver speeds on curves, which ideally result in successful curve negotiation and fewer crashes. Dynamic speed feedback sign (DSFS) systems are traffic control devices that have been used to reduce vehicle speeds successfully and, subsequently, crashes in applications such as traffic calming on urban roads. DSFS systems show promise, but they have not been fully evaluated for rural curves. To better understand the effectiveness of DSFS systems in reducing crashes on curves, a national field evaluation of DSFS systems on curves on rural two lane roadways was conducted. Two different DSFS systems were selected and placed at 22 sites in seven states. Control sites were also identified. A full Bayes modeling methodology was utilized to develop crash modification factors (CMFs) for several scenarios including total crashes for both directions, total crashes in the direction of the sign, total single-vehicle crashes, and single-vehicle crashes in the direction of the sign. Using quarterly crash frequency as the response variable, crash modification factors were developed and results showed that crashes were $5 \%$ to $7 \%$ lower after installation of the signs depending on the model.
\end{abstract}

\section{Keywords}

CMF, Curve Warning, Dynamic Speed Feedback Sign, Bayesian Modeling, Horizontal Curve, Rural Curve, Speed Warning, Rural Safety

\footnotetext{
${ }^{*}$ Corresponding author.
}

How to cite this paper: Hallmark, S.L., Qiu, Y., Hawkins, N. and Smadi, O. (2015) Crash Modification Factors for Dynamic Speed Feedback Signs on Rural Curves. Journal of Transportation Technologies, 5, 9-23. 


\section{Introduction}

\subsection{Background}

Horizontal curves are a particular safety concern since they have a disproportionate number of crashes compared to tangent sections. Glennon et al. [1] reported that curves have approximately three times the crash rate of tangent section and the majority of those crashes are lane departures. Preston [2] reports that $25 \%$ to $50 \%$ of severe road departure crashes in Minnesota occur on curves, even though curves account for only $10 \%$ of the system mileage. Shankar et al. [3] evaluated divided state highways without median barriers in Washington State and found a relationship between the number of horizontal curves per kilometer and median crossover crashes. Farmer and Lund [4] evaluated single-vehicle fatal and injury rollover crashes using logistic regression and found that the odds of having a rollover on a curved section were 1.42 to 2.15 times that of having a rollover on a straight section.

Curve crashes are predominantly roadway departures. A total of $76 \%$ of curve-related fatal crashes are single vehicles leaving the roadway and striking a fixed object or overturning. Another $11 \%$ of curve-related crashes are head-on collisions [5]. The frequency and severity of curve-related crashes have been correlated to a number of geometric factors including radius, degree of curve, length of curve, type of curve transition, lane and shoulder widths, preceding tangent length, and required speed reduction [6]-[10]. Findley et al. [11] found that more closely spaced curves have fewer predicted crashes than curves that are farther apart.

Although curve-related crashes are correlated to geometric factors, driver factors are the main contributors to roadway departure in general and curve related crashes in specific. Driver distraction, impairment, and speed are the primary contributing factors.

Driver speed is a major factor in whether drivers will be able to negotiate a curve successfully. Council et al. [12] evaluated National Highway Traffic Safety Association (NHTSA) Fatality Analysis Reporting System (FARS) data and found that $29.5 \%$ of all fatal crashes were speeding-related. The researchers conducted several different types of analyses and found that single-vehicle run-off-road crashes were more likely to be speedingrelated compared to multi-vehicle crashes. Crashes on curves were more likely to be speeding-related compared to tangent section and nighttime crashes. In addition, FARS data indicated that $54 \%$ of speeding-related rollover/ overturn, jackknife, or fixed object crashes were on curves.

Fatality Analysis Reporting System (FARS) data were evaluated to determine characteristics of speeding-related fatal roadway departure crashes. FARS data from 2010 to 2012 were examined by the authors. Crashes in FARS were coded as "speeding-related" if the driver was charged with a speeding-related offense or if an officer indicated that racing, driving too fast for conditions, or exceeding the posted speed limit was a contributing factor in the crash [13]."

Roadway departure crashes are identified using the most recent definition provided by FHWA defined as a crash where a vehicle crosses an edge line, centerline, or leaves the traveled way.

Around $40 \%$ of roadway departure crashes are speeding-related. Thirty eight percent of vehicles involved in fatal roadway departure crashes were coded as being on a curve. Vehicles involved in fatal roadway departure crashes on curves were indicated as being speeding-related $47.3 \%$ of the time compared to only $30 \%$ on tangent sections.

\subsection{Effectiveness of General Rural Curve Treatments}

A number of speed management countermeasures have been employed to reduce speed and subsequently crashes on curves. Design solutions, such as paved shoulders, have generally been effective [9] [14] [15]. However they are also expensive and may need to be programed into rehabilitation or reconstruction activities.

Mixed results have been demonstrated for raised pavement markers (RPMs). Decreases in crashes of up to $33 \%$ have been found while a few studies have reported increases [16]-[18]. Additionally some concern has been raised about RPMs becoming dislodged from the pavement surface and creating a safety hazard.

Pavement markings treatments such as on-pavement curve signing, wider edge lines or centerlines, transverse markings, etc. have been applied with reasonable success. Change in crashes due to wider edge/centerlines have ranged from a decrease of $62 \%$ to an increase of $5 \%$ [19] [20]. However, several studies indicated no change in crashes [21]-[24]. Transverse markings (i.e. optical speed bars, converging chevrons) have been applied in a limited number of applications on rural roadways. Most studies have reported speed reduction rather than crash 
reduction with mean speed reductions ranging from a decrease of $-5.9 \mathrm{mph}$ to an increase of $4.2 \mathrm{mph}$. On pavement curve signing has resulted in decreases in mean speed of up to $4 \mathrm{mph}$ [25]-[27].

The main drawback to pavement markings is regular maintenance. Additionally pavement markings can become obscured during winter weather events.

Vertical delineation, such as post mounted delineators (PMDs) or additional reflective material on chevron posts, have had mixed results. PMDs have reduced speeds in several studies by up to $8.7 \mathrm{mph}$ [28] [29]. In some cases speeds have increased by up to $3.1 \mathrm{mph}$. Full-post reflective treatment added to chevron posts has a range of effectiveness from decreases up to $2.2 \mathrm{mph}$ to increases of $1.2 \mathrm{mph}$ [27] [28].

Rumble strips and stripes provide audible and vibratory alerts to drivers when their vehicles depart the travel lane and notify drivers that a steering correction is needed. A number of studies have been conducted about the effectiveness of both centerline and shoulder rumble strips with most studies indicating substantial reductions in crashes [30]-[33]. A few studies did show increases in crashes [31]-[33]. The main drawbacks to rumble strips are cost, potential noise issues, and possible danger to bicyclists and horse drawn vehicles. Some concerns have been raised about pavement performance with grooving as well. Additionally shoulder rumble strips require some amount of paved shoulders which many rural 2-lane roadways do not have.

\subsection{Effectiveness of Dynamic Speed Feedback Sign Systems}

Dynamic speed feedback sign (DSFS) systems are one type of traffic control device that has been used to reduce vehicle speeds successfully and, subsequently, crashes in applications such as traffic calming on urban roads. DSFS consist of a speed measuring device, which may be loop detectors or radar, and a message sign that displays feedback to those drivers who exceed a predetermined speed threshold. The feedback may be the driver's actual speed, a message such as SLOW DOWN, or activation of some warning device, such as beacons or a curve warning sign.

DSFS systems have been tested and proven effective in urban applications such as school zones. They can be installed reasonably quickly and can be moved to other location if not effective at a particular location. One of the main advantages is that DSFS are set to activate only when drivers are exceeding a set speed threshold which targets only problem drivers. Although DSFS are promising, their effectiveness for rural applications, such as rural curves has not yet been well explored.

Several studies have looked at the effectiveness of DSFS in rural settings. Bertini et al. [34] studied the effectiveness of a DSFS at a curve on Interstate 5 in Oregon. Results indicated that, after installation of the DSFS system, passenger vehicle speeds were reduced by $2.6 \mathrm{mph}$ and commercial truck speeds were reduced by 1.9 mph, with the results being statistically significant at the $95 \%$ confidence level.

Tribbett et al. [35] evaluated dynamic curve warning systems for advance notification of alignment changes and speed advisories at five sites in the Sacramento River Canyon on Interstate 5 in California. The roadway has high traffic volumes (7650 to 9300 vehicles per day/vpd), mountainous terrain, and a number of heavy vehicle crashes. The signs were 10 by 7 foot full-matrix LED panels that could be programmed to display a variety of messages. Messages used by the researchers included curve warnings and driver speed feedback. Data were collected before and at several periods after installation of the signs. In general the researchers found decreases in mean truck speeds up to $5.4 \mathrm{mph}$ and decreases of up to $4.5 \mathrm{mph}$ in passenger speeds. Passenger speeds increased at one location with increases up to $7.8 \mathrm{mph}$.

The City of Bellevue Washington installed and evaluated a number of DSFS systems, including two which were used as curve advisory warnings [36]. Both were on urban arterials (35 and $25 \mathrm{mph}$ speed limits). Speeds were collected before and between 18 months and two years after installation of the signs. One sign showed a $3.3 \mathrm{mph}$ reduction in 85th percentile speed and the other showed a $3.5 \mathrm{mph}$ reduction.

Mattox et al. [37] looked at the effectiveness of a DSFS system on secondary highways in South Carolina. This system consisted of a radar device and a 4 by 4 foot yellow sign with 6 inch lettering reading: YOU ARE SPEEDING IF FLASHING. In addition, there were two 1 by 1 foot orange flags and a type B flashing beacon light. Results showed that overall mean speed and 85th percentile speeds were reduced by approximately $3 \mathrm{mph}$.

A study by the 3M Company [38] evaluated driver speed feedback signs in the United Kingdom. Signs were tested at various locations in Doncaster, including semi-rural roadways. The signs displayed the approaching driver speed. The sites had speed limits of $40 \mathrm{mph}$ and reductions up to $7 \mathrm{mph}$ in 85th percentile speeds were noted. 
Three vehicle-activated curve warning signs were placed on curves on two-lane roads in Norfolk, Wiltshire, and West Sussex [39]. The sign displays were blank when the driver was under a specified speed threshold and displayed the curve sign when a driver exceeded the threshold (50th percentile speed). Mean speeds were reduced by 2.1 to $6.9 \mathrm{mph}$. Crash data were available for two sites, and the researchers found that crashes decreased by $54 \%$ and $100 \%$.

Santiago-Chaparra et al. [40] studied the effectiveness of a dynamic speed feedback sign on a rural two lane highway in Wisconsin. The DSFS displayed a flashing speed reading when an approaching vehicle was above the speed limit and provided a steady display when the approaching vehicles speed was below the speed limit. Speed trajectories were collected upstream and downstream of the DSFS. They found that the signs were the most effective 1200 to 1400 feet upstream of the sign and that the impact began to wane 300 to 500 feet past the DSFS.

All of the studies described above showed a decrease in speed suggesting the utility of DSFS in rural applications. However, all of the studies cited above had limited sample sizes. In most cases only one or two signs were evaluated. Additionally, several were tested on freeways and were typically overhead signs which are not practical for rural two-lane applications. Finally, only one study evaluated the crash impacts of the signs. And only a simple before and after comparison of two sites was available.

Another drawback to most of the above studies is that data were only collected for a short period after installation of the DSFS. Drivers often acclimate to treatments and as a result, treatments may become less effective over time.

As a result, the goal of this research was to provide a more robust assessment of the crash impacts of DSFS on rural curves than has previously been available. The study had sufficient resources to evaluate several sites in multiple states as described in the following sections.

\subsection{Research Project Objectives}

Driver speed is a major factor in curve related crash risk. A number of speed management countermeasures have been employed to reduce speed and subsequently crashes on curves. Design solutions, such as realignment, are expensive. Pavement markings require regular maintenance and rumble strips cause potential noise issues.

Dynamic speed feedback sign (DSFS) systems are traffic control devices that have been used to reduce vehicle speeds successfully and, subsequently, crashes in applications such as speed management on urban roads. Several studies have evaluated their effectiveness in rural setting but most have only evaluated the speed impacts and most have a very limited sample size. Although DSFS systems show promise for rural applications, they have not been fully evaluated in rural settings and most studies which have evaluated their effectiveness have assessed the effectiveness for speed management than crash reduction.

To better understand the effectiveness of DSFS systems on safety risk at rural two-lane curves, a national field evaluation was conducted. Twenty-two DSFS signs were placed in seven states and their effectiveness in reducing speed and crashes were evaluated using before and after analyses. The signs were generally very effective in reducing speed as reported by Hallmark et al., (2013). Crash modification factors were also developed using a Bayesian analysis and are the focus of this paper.

\section{Site and Sign Selection}

\subsection{Description of Site Selection}

The objective of this research project was to conduct a national evaluation of the effectiveness of DSFS systems on rural curves. The team made every effort to obtain geographic diversity in selecting states where the signs would be tested. Potential sites were selected in seven states (Arizona, Florida, Iowa, Ohio, Oregon, Texas, and Washington) in conjunction with the local or state agency. During site selection, crash data were collected for three years prior to the request. Information about initially recommended sites were reviewed in the office and sites for each state with the largest number of crashes that did not have any adverse geometry or conditions that would have made the site infeasible, such as a railroad or major intersection within the curve, were identified.

Next, site visits were made to each state and the potential sites were field surveyed. During site visits, the team conducted a brief speed study using a radar gun to ensure that a speeding problem existed (defined as mean or 85th percentile that was 5 or more mph over the posted or advisory speed). After the site visits, the team se- 
lected final sites based on the number and type of crashes, whether a speeding problem existed, and other site suitability factors. A total of 51 viable sites across the seven study states resulted.

A set number of signs were allocated to each state so the researchers randomly selected sites within each state for treatment. Two to four signs were installed in each state for a total of 22 test sites in seven states. The remaining 29 sites served as control sites for the crash analysis.

Tangent speeds ranged from 50 to $75 \mathrm{mph}$ and advisory speeds ranged from $15 \mathrm{mph}$ to no advisory speed. Crashes ranged from 0.7 to 5.2 crashes per year with an average of 1.9 crashes per year.

\subsection{Description of Sign Selection}

A DSFS consists of a speed measuring device (loop detectors or radar) and a message sign that displays feedback to drivers who exceed a predetermined speed threshold. The feedback may be the driver's actual speed, a message such as "SLOW DOWN," or activation of some warning device, such as beacons or a curve warning sign.

When selecting DSFS systems, the team focused on the type of feedback provided by the variable message sign. The most common variable message sign simply displays a vehicle's speed when it is exceeding a set threshold. The sign can also activate a flashing beacon when the speed threshold is exceeded. Several sign type can also display a static message. Common messages include "SLOW DOWN" or "TOO FAST". More complex signs allow programming of a message, with the message being limited only by the number of alphanumeric characters that can be displayed on the sign.

To select final DSFS systems, the research team developed a set of minimum criteria, which included the following:

- Have the capability to be permanently mounted on a standard wood or metal pole

- Have the ability to display a warning and/or a simple message (e.g., XX mph, TOO FAST)

- Be durable enough to survive the two-year study period and perform in different climates

- Have self-contained power (e.g., A/C or solar)

- Cost less than $\$ 10,000$ per sign (including installation, support, and maintenance)

- Metal 1 applicable Manual on Uniform Traffic Control Devices (MUTCD) for Streets and Highways [41] requirements or could be approved

- Project a clear, bright, non-glare, easily readable message to motorists

\subsection{Sign Displays}

Two different types of DSFS systems were selected for evaluation. One displays a curve warning sign (Figure 1) and the second displays vehicle speed (Figure 2). It should be noted that, in all cases, the signs were considered supplementary traffic control devices.

The curve display sign was dark (not illuminated) for drivers traveling at or below the 50th percentile speed for the site. The 50th percentile speed was determined using speed data collected before each sign was installed. For drivers traveling over the 50th percentile speed, the sign displays the corresponding MUTCD curve advisory sign, which is based on the type of curve (i.e., W1-2 sign).

The speed display sign was also blank for drivers traveling at or below the 50th percentile speed. The sign displayed actual vehicle speed (YOUR SPEED XX) for drivers traveling over the 50th percentile speed up to 20 mph over the posted speed limit. Drivers traveling 20 or more mph over the speed limit received a "SPEED LIMIT XX” message. This was done to avoid having drivers use the sign to test their speed.

\subsection{Sign Installation and Maintenance}

Once sites were selected, signs were ordered by the team and then installed in conjunction with the corresponding agency. The first set of signs were installed in July 2008 and the last four signs were installed in April 2010.

One sign was installed at each site. As a result, each sign was visible to drivers in only one direction. The direction of travel where the most speed-related crashes had occurred was selected as the direction for installation. In all cases, this turned out to be the direction in which vehicles were traversing the outside of the curve. The sign was installed at the PC for the selected direction.

Speed data were collected at various intervals over the course of 2 years. As a result, the team were able to 


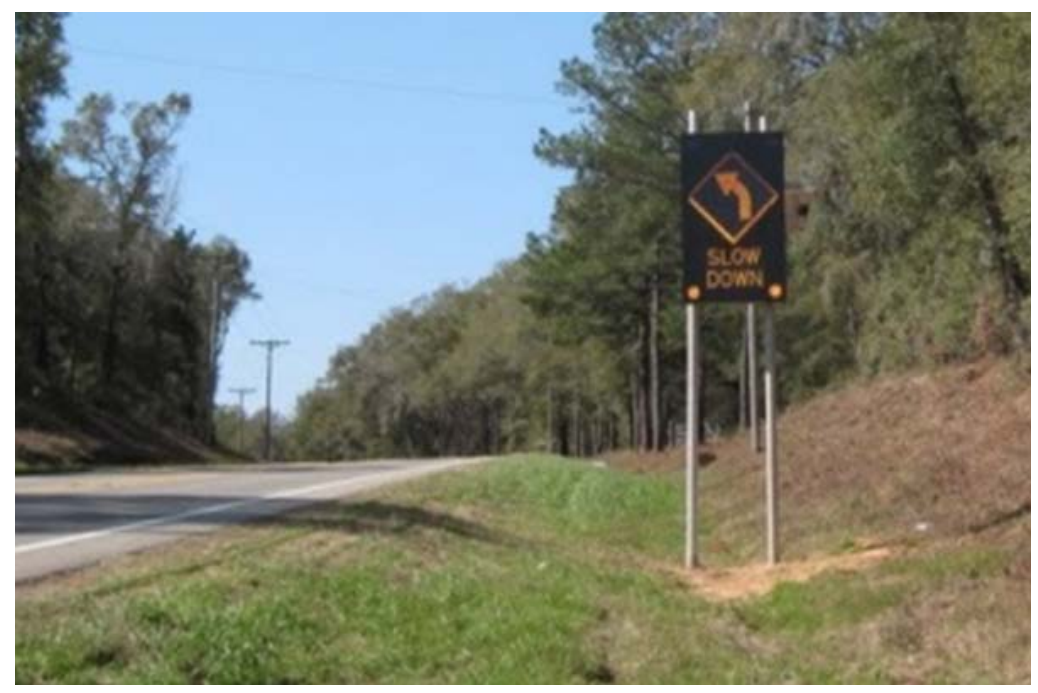

Figure 1. Curve warning display sign used in the study.

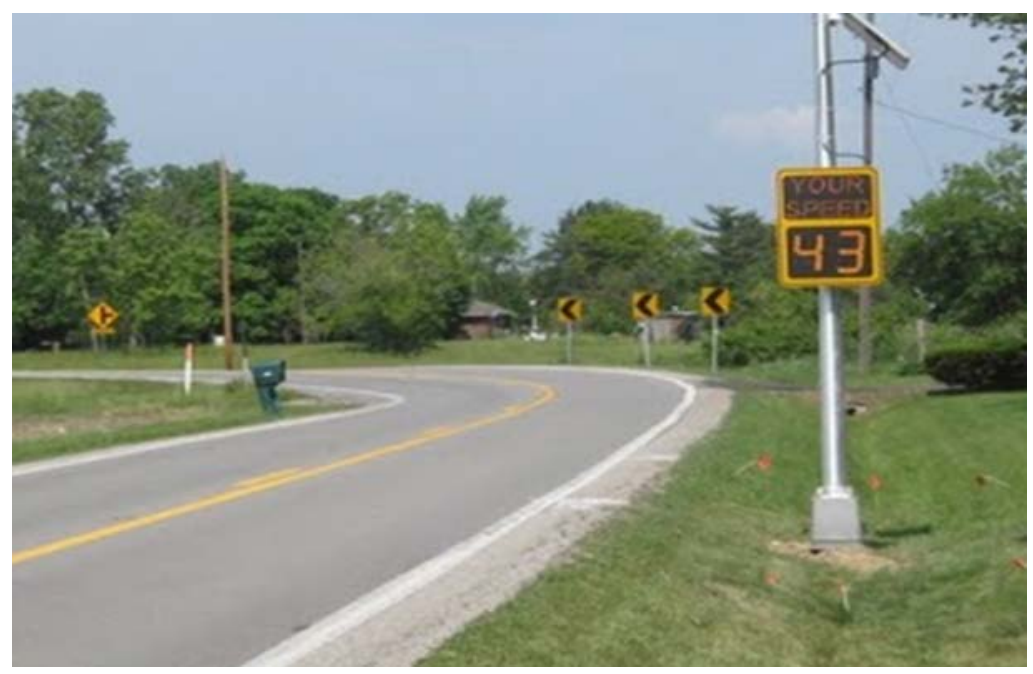

Figure 2. Speed feedback display sign used in the study.

periodically check sign functionality. Additionally, the corresponding agency monitored the signs and alerted the team when a sign was not functioning. In several cases, signs were vandalized. In most cases, the signs were fixed or replaced as soon as possible after problems were noted. The time period when a sign was not functioning was also noted.

\section{Method}

During site selection, crash data for three years before installation of the signs were requested from the corresponding state or county agency. Once the signs were installed for at least two years, the team contacted the corresponding agency again and requested crash data for the intervening period from the original data request before sign installation up to the most recent available data. In all cases the team received a list of individual crashes with characteristics such as date, direction of crash, etc. The installation date for each curve was used to establish the before and after period.

When signs were installed early in the study, this typically resulted in more than two years of after data and when signs were installed later in the study, this resulted in more than three years of before data. As a result, crash data were collected for up to four years before and up to three years after sign installation depending on the state. 


\subsection{Covariates}

Several models were developed that included different types of crashes. In all cases, quarterly crash frequency was the response variable used. The year and quarter when each crash occurred was derived from the crash data. Crashes were aggregated to quarters rather than years due to the limited amount of after period data available. The use of quarters allowed the quarter in which installation occurred to be filtered from the analysis without having to exclude the entire installation year. In addition, if a malfunction occurred and the sign was inoperable, the quarter in which the signs were non-functional could also be excluded from the analysis.

The use of quarters also allowed season to be included as a covariate. A relationship between crashes and season is expected, given more crashes may occur during a particular season. Quarters were aggregated to months with similar weather as follows:

- Winter (December, January, February)

- Spring (March, April, May)

- Summer (June, July, August)

- Fall (September, October, November)

In addition, use of season as a covariate allowed differences that may have occurred due to an unequal distribution of quarters in the before and after period to be accounted for. Four different models were developed:

Total crashes for both directions of travel

Total crashes in the direction of the sign for treatment sites or outside of curve for control sites

Single-vehicle (SV) crashes for both directions of travel

SV crashes by direction in the direction of the sign for treatment sites or outside of curve for control sites

Crashes for vehicles traveling in the direction of the DSFS sign were evaluated separately given the sign was most likely to reduce crashes for vehicles traveling in that direction. A model was also developed for crashes in both directions (total crashes) given that slowing vehicles in one direction may have some impact on vehicle speeds in the opposite direction.

As noted in Section 2, one sign was installed at each site in the direction in which most crashes had occurred. In all cases, this was the direction in which vehicles were traversing the outside of the curve. As a result, the primary direction for control sites was vehicles traversing the outside of the curve. When aggregated by direction, crashes for single vehicles traveling in the primary direction and multi-vehicle crashes where one or more vehicles were traveling in the primary direction were included.

In addition, an attempt was made to develop a model for fatal crashes. However, the number of fatal crashes per site was low and there were not sufficient data to develop a reliable model.

Annual average daily traffic (AADT) was used as a measure of exposure. Given the study period was fairly short-term, in most cases AADT was the same or similar for the before and after periods.

When possible, the team requested crash data for only the curve of interest (treatment or control curve). However, states geolocate crashes differently so, in some cases, the agency provided crashes for a section that may have included adjacent curves and some tangent sections. In all cases, the same section was used for the before and after period. To account for differences in curve and section length, section length was also modeled as a covariate.

Table 1 describes the covariates included in the models. Roadway width and shoulder type were similar across sites (11 to 12 foot lanes, earth/gravel shoulders), so these variables were not included in the analysis.

\subsection{Development of Crash Modification Factors Using a Full Bayes Model}

A before-and-after analysis was conducted using a full Bayes (FB) model to develop crash modification factors (CMFs). Expected crash rates are represented by safety performance functions (SPFs) that relate the expected crash rate to traffic and road characteristics.

The Bayesian method accounts for regression-to-the-mean effects that result from the natural tendency to select treatment sites with high observed crash frequencies. Control sites were similar to treatment sites in terms of traffic volume, geometry, location, and crashes. (A discussion of how treatment and control sites were selected is provided in Section 2.)

In the literature, SPF estimation in the context of before-and-after analysis has been conducted via the empirical Bayes (EB) approach in conjunction with negative binomial model structure [42]-[44]. The estimated SPF is used to predict treatment site crash rates that would have occurred without the treatment [45]. 
Table 1. Description of covariates.

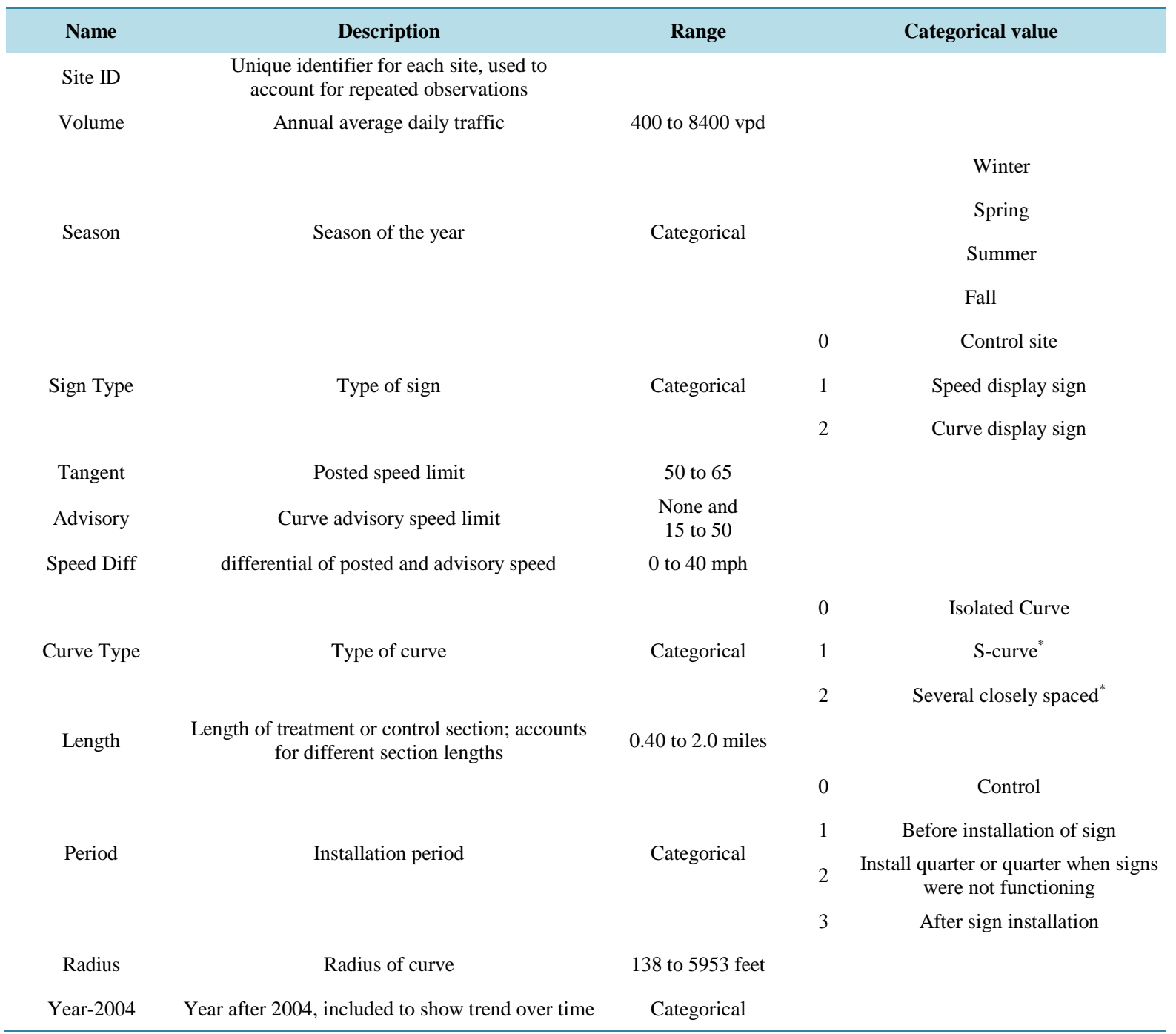

*About 500 feet or less spacing between curves.

The predicted crash rates are then compared with the observed crash counts during the after period to develop CMFs. Although many studies have employed an EB approach, the team felt that a full Bayesian (FB) approach was more appropriate. The advantages of the FB as compared to the EB approach are noted as follows:

Takes into account all uncertainties in the analysis

Provides more detailed causal inferences [46]

Requires fewer data

- Has more flexibility in selecting crash count distributions [47]

\subsubsection{Model Development}

The dataset included 624 observations for control sites and 492 observations for treatment sites. Year was considered as covariate in the regression term to account for changes over time. Correlations between observations, from the same section, were accounted for as within-subject errors in the model.

As noted in Section 3.1, four separate models were developed: total and single-vehicle crashes in both directions and in the direction of the treatment/outside of curve. Quarterly crashes were the response variable. Crash counts across years and sites were expressed by the following general model [48]:

$$
\text { Crash counts }=\text { trend }+ \text { regression term }+ \text { random effects }
$$


where trend counts for the effect of time, the regression term is of the same form as SPFs used in EB studies [43] [49], and random effects account for latent variables across the sites. Correlations between observations from the same section were accounted as the within-subject errors in the model.

\subsubsection{Model Form and Selection Criteria}

To find the appropriate model for the FB analysis, several models were tested. A zero inflated model (ZIP and ZINB) was evaluated against the plain count model (Poisson and Negative Binomial) followed by the Vuong test. Both zero inflated Poisson and Poisson-Gamma (NB) models were selected. Then, after applying the FB method, deviance information criterion (DIC) was used to compare the different Bayesian hierarchical models with a difference of more than 10 indicating incomparable of one with DIC [50].

The models were developed using the following where $Y_{i, t}$ is the observed number of crashes at site $i$ in year $t, \lambda_{i, t}$ is the expected number of crashes at site $i$ in year $t, \varepsilon_{i}$ is the multiplicative random effect at site $i$, Xi, and $t$ is the corresponding covariates such as traffic and road conditions. The expressions of all models compared are as follows:

$$
\begin{aligned}
& \text { Model } A(Z I P): Y_{i t} \sim \operatorname{ZIP}\left(\pi_{i, t}, \varepsilon_{i} l_{i, t}\right) \\
& \text { where } \ln l_{i, t}=a 1+X 1_{i t}^{\prime} \beta_{1}+\gamma_{1}(t-2004) \text { and } \log i t\left(\pi_{i, t}\right)=a_{2}+X 2_{i, t} \beta_{2}+\gamma_{2}(t-2004)
\end{aligned}
$$

Model $B(Z I N B): Y_{i, t} \sim \operatorname{ZIP}\left(\pi_{i, t}, \varepsilon_{i} l_{i, t}\right)$

where $\ln l_{i, t}=a_{1}+X 1^{\prime} \beta_{1}+\gamma_{1}(t-2004), \log i t\left(\pi_{i, t}\right)=a_{2}+X 2^{\prime} \beta_{2}+\gamma_{2}(t-2004)$ and $\varepsilon_{i} \sim \operatorname{Gamma}(\phi, 1 / \phi)$

\subsubsection{Prior Choices for FB Methodology}

Prior distributions for parameters $\left(\alpha_{1}, \alpha_{2}, \beta_{1}, \beta_{2}, \gamma_{1}, \gamma_{2}\right)$ are assumed non-informative $\mathrm{N}\left(0,10^{3}\right)$ to reflect the lack of precise knowledge of the value of the coefficients. The prior distribution for parameter $\phi$ is assumed Gamma $(1,1)$. The posterior distributions were calibrated using Monte Carlo Markov Chain (MCMC) methods [51] [52] using all data from the control sites and the before period data for the treated sites.

\subsubsection{Development of CMFs}

The CMFs were calculated as follows (Equation (1)):

$$
C M F=\frac{\sum_{i=1}^{n} \sum_{t=T+1}^{T+m} Y_{i, t}}{\sum_{i=1}^{n} \sum_{t=T+1}^{T+m} \lambda_{i, t}}
$$

where $n$ is the number of treated sites, $m$ is number of years after treatment, $T$ is the last year before treatment, and $\lambda_{i}, t$ is expected crashes without treatment for intersection $i$ in year $t$ in the after period. The corresponding standard error (STDE) for the CMF was calculated using Equation (2):

$$
\operatorname{STDE}(C M F)=C M F \times \sqrt{\frac{\operatorname{Var}\left(\sum_{i=1}^{n} \sum_{t=T+1}^{T+m} Y_{i, t}\right)}{\left(\sum_{i=1}^{n} \sum_{t=T+1}^{T+m} Y_{i, t}\right)^{2}}+\frac{\operatorname{Var}\left(\sum_{i=1}^{n} \sum_{t=T+1}^{T+m} \lambda_{i, t}\right)}{\left(\sum_{i=1}^{n} \sum_{t=T+1}^{T+m} \lambda_{i, t}\right)^{2}}}
$$

\section{Results}

\subsection{Model Statistics}

The safety effect of installing the DSFS was developed using the described methodology. As noted in Section 3, four different models were developed. Results for each model are presented below. The best model for each of the four scenarios was chosen with $95 \%$ significant covariates using DIC. Table 2 shows the parameter estimates for the best fit model for all crashes in both directions. 
Table 2. Parameter estimations for ZIP model for total crashes in both directions.

\begin{tabular}{ccc}
\hline Parameter & Posterior mean & P-value \\
\hline Intercept & -7.4295 & $<0.0001$ \\
Log (volume) & 0.6456 & $<0.0001$ \\
Length & 0.6784 & $<0.0001$ \\
Speed Diff & 0.0432 & $<0.0001$ \\
S-curve vs. single curve & -0.3602 & 0.0174 \\
Multiple vs. single curve & 0.1819 & 0.0002 \\
Spring vs. winter & -0.1159 & 0.3239 \\
Summer vs. winter & -0.3105 & 0.0202 \\
Fall vs. winter & -0.3247 & 0.0128 \\
2005 vs. 2011 & 1.3004 & $<0.0001$ \\
2006 vs. 2011 & 1.0324 & $<0.0001$ \\
2007 vs. 2011 & 1.0054 & $<0.0001$ \\
2008 vs. 2011 & 0.8083 & 0.0005 \\
2009 vs. 2011 & 0.4502 & 0.0693 \\
2010 vs. 2011 & 0.8056 & 0.0005 \\
Intercept & Parameters for probability model & -3.9830 \\
\hline
\end{tabular}

Table 3 shows the parameter estimates for the best fit model for total crashes in the direction of the DSFS for treatment sites and control sites.

Table 4 shows the parameter estimates for the best fit model for single-vehicle crashes in both directions.

Table 5 shows the parameter estimates for the best fit model for single-vehicle crashes in the direction of the DSFS for treatment sites or control sites.

\subsection{Crash Modification Factors}

Table 6 lists the CMFs and associated parameters for the four models that were developed.

Based on the estimated coefficients, predicted crashes per year after installing the DSFS were calculated as shown in Table 6. The predicted number of crashes was calculated by estimating crashes for each quarter for each treatment site and summing the predicted crashes for the after period. CMFs were calculated by dividing the observed crashes by the predicted values.

For total crashes in both directions, for example, the CMF is calculated as 52.1/54.6 = 0.95. In other words, total crashes for both directions are expected to decrease by $5 \%$ and all crashes in the direction of the DSFS are expected to decrease by 7\%. Single-vehicle crashes in both directions are expected to decrease by 5\% and single-vehicle crashes in the direction of the sign are expected to decrease by $5 \%$.

To determine whether the reduction due to the treatment was significant or not, 95\% confidence intervals (CIs) for the CMFs were calculated and are shown in Table 6. For example, the 95\% CI for all crashes in both directions is $[0.95 \pm 1.96 \times 0.01]=[0.93,0.97]$, not containing 1 , so the crash reduction for all crash types is statistically significant.

Results of the statistical analyses indicate that the DSFS results in a crash reduction ranging from $7 \%$ to $5 \%$.

\section{Conclusions}

The study developed crash modification factors for dynamic speed feedback signs that were installed on rural two-lane curves at 22 sites across seven states. Control sites with similar characteristics were included in the 
Table 3. Parameter estimations for ZIP model for total crashes in one direction.

\begin{tabular}{ccc}
\hline Parameter & Posterior mean & P-value \\
\hline Intercept & -8.0551 & $<0.0001$ \\
Log (volume) & 0.6992 & $<0.0001$ \\
Length & 0.7602 & $<0.0001$ \\
Speed Diff & 0.0278 & 0.002 \\
S-curve vs. single curve & 0.1061 & 0.5443 \\
Multiple vs. single curve & 0.4392 & 0.0463 \\
Spring vs. winter & -0.3236 & 0.0460 \\
Summer vs. winter & -0.3088 & 0.06604 \\
Fall vs. winter & -0.5034 & 0.004 \\
2005 vs. 2011 & 1.2227 & $<0.0001$ \\
2006 vs. 2011 & 0.9846 & 0.0005 \\
2007 vs. 2011 & 0.9411 & 0.0009 \\
2008 vs. 2011 & Parameters for probability model & 0.0476 \\
2009 vs. 2011 & 0.5879 & 0.3684 \\
2010 vs. 2011 & 0.2842 & 0.0158 \\
Intercept & 0.6984 & 0.006 \\
\hline
\end{tabular}

Table 4. Parameter estimations for ZIP model for SV crashes in both directions.

\begin{tabular}{ccc}
\hline Parameter & Posterior mean & P-value \\
\hline Intercept & -7.5668 & $<0.0001$ \\
Log (volume) & 0.5629 & $<0.0001$ \\
Length & 0.7287 & $<0.0001$ \\
Speed Diff & 0.0382 & $<0.0001$ \\
S-curve vs. single curve & -0.3182 & 0.0578 \\
Multiple vs. single curve & 0.2889 & 0.0003 \\
Spring vs. winter & -0.0413 & 0.6621 \\
Summer vs. winter & -0.3927 & 0.0117 \\
Fall vs. winter & -0.2790 & 0.0542 \\
2005 vs. 2011 & 1.7834 & $<0.0001$ \\
2006 vs. 2011 & 1.5176 & $<0.0001$ \\
2007 vs. 2011 & 1.3917 & $<0.0001$ \\
2008 vs. 2011 & Parameters for probability model & $<0.0001$ \\
2009 vs. 2011 & -4.3494 & 0.0048 \\
2010 vs. 2011 & 0.1238 & $<0.0001$
\end{tabular}


Table 5. Parameter estimations for ZIP model for SV crashes in one direction.

\begin{tabular}{ccc}
\hline Parameter & Posterior mean & P-value \\
\hline Intercept & -7.7523 & $<0.0001$ \\
Log (volume) & 0.5269 & $<0.0001$ \\
Length & 0.7984 & $<0.0001$ \\
Speed Diff & 0.0329 & $<0.0001$ \\
S-curve vs. single curve & 0.2163 & 0.2721 \\
Multiple vs. single curve & 0.6136 & 0.0398 \\
Spring vs. winter & -0.3131 & 0.0936 \\
Summer vs. winter & -0.3916 & 0.0502 \\
Fall vs. winter & -0.5374 & 0.0071 \\
2005 vs. 2011 & 1.6955 & $<0.0001$ \\
2006 vs. 2011 & 1.4447 & $<0.0001$ \\
2007 vs. 2011 & Parameters for probability model & 0.0005 \\
2008 vs. 2011 & -1.2980 & 0.0226 \\
2009 vs. 2011 & 0.8900 & 0.1093 \\
2010 vs. 2011 & 0.6567 & 0.0040
\end{tabular}

Table 6. Results for calculation of crash modification factors.

\begin{tabular}{cccccc}
\hline Crash Type & Direction & Observed Crashes & Estimated Crashes & CMF (SE) & 95\% CI \\
\hline Total & Both & 52.1 & 54.6 & $0.95(0.01)$ & $0.93,0.97$ \\
Total & Toward sign/outside of curve & 32.5 & 34.8 & $0.93(0.02)$ & $0.89,0.97$ \\
Single-vehicle & Both & 38.6 & 40.7 & $0.95(0.01)$ & $0.93,0.97$ \\
Single-vehicle & Toward sign/outside of curve & 22.3 & 23.4 & $0.95(0.02)$ & $0.91,0.99$ \\
\hline
\end{tabular}

analysis. Two different signs were evaluated. One shows speed for vehicles traveling over the 50th percentile speed and the second displays the corresponding curve warning sign.

A full Bayes analysis was used to develop the CMFs. Results indicate that crashes were 5\% to 7\% lower after installation of the sign depending on type and direction of crash. No difference was noted between sign type.

Results of a speed analysis, which was discussed further by Hallmark et al. [53], indicated that significant reductions in speed resulted and that the reductions were sustained for the most part over the two-year analysis period.

Although the signs were effective in reducing both speed and crashes, the signs were relatively expensive (approximately $\$ 10,000$ per sign installed). As a result, agencies should continuously consider trade-offs and advantages and disadvantages of site specific safety countermeasure when implementing safety strategies.

\section{Acknowledgements}

The authors would like to thank the Federal Highway Administration, the Midwest Transportation Consortium, the Iowa Department of Transportation, the Iowa Highway Research Board, and the Texas Department of Transportation for sponsoring this research. We would also like to thank the corresponding state and local agen- 
cies who worked with us to select and install treatments. The Center for Transportation Research and Education also thanks the Texas Transportation Institute and Portland State University for their partnership on this research.

\section{Highlights}

Dynamic speed feedback signs were installed on rural two-lane curves at 22 sites across seven states.

Crash modification factors for dynamic speed feedback signs were developed using a full Bayes analysis.

Results of the statistical analyses indicate crash reductions ranging from $5 \%$ to $7 \%$.

Although the signs were effective in reducing both speed and crashes, the signs are relatively expensive.

\section{References}

[1] Glennon, J.C., Neuman, T.R. and Leisch, J.E. (1985) Safety and Operational Considerations for Design of Rural Highway Curves. Federal Highway Administration. FHWA/RD-86-035.

[2] Preston, H. and Schoenecker, T. (1999) Potential Safety Effects of Dynamic Signing at Rural Horizontal Curves. Minnesota Local Road Research Board.

[3] Shankar, V.N., Albin, R.B., Milton, J.C. and Mannering, F.L. (1998) Evaluating Median Crossover Likelihoods with Clustered Accident Counts: An Empirical Inquiry Using the Random Effects Negative Binomial Model. Transportation Research Record: Journal of the Transportation Research Board, 1635, 44-48.

[4] Farmer, C.M. and Lund, A.K. (2002) Rollover Risk of Cars and Light Trucks after Accounting for Driver and Environmental Factors. Accident Analysis and Prevention, 34, 163-173. http://dx.doi.org/10.1016/S0001-4575(01)00010-0

[5] AASHTO (2008) Driving Down Lane-Departure Crashes: A National Priority. American Association of State Highway and Transportation Officials.

[6] Luediger L., Choueiri, E.M., Hayward, J.C. and Paluri, A. (1988) Possible Design Procedure to Promote Design Consistency in Highway Geometric Design on Two-Lane Rural Roads. Transportation Research Record: Journal of the Transportation Research Board, 1195, 111-122.

[7] Miaou, S. and Lum, H. (1993) Statistical Evaluation of the Effects of Highway Geometric Design on Truck Accident Involvements. Transportation Research Record: Journal of the Transportation Research Board, 1407, 11-24.

[8] Vogt, A. and Bared, J. (1998) Accident Models for Two-Lane Rural Segments and Intersections. Transportation Research Record: Journal of the Transportation Research Board, 1635, 18-29.

[9] Zegeer, C.V., Stewart, R., Council, F.M., Reinfurt, D.W. and Hamilton, E. (1992) Safety Effects of Geometric Improvements on Horizontal Curves. Transportation Research Record: Journal of the Transportation Research Board, 1356, 11-19.

[10] Caliendo, C., Guida, M. and Parisi, A. (2007) A Crash-Prediction Model for Multi-lane Roads. Accident Analysis and Prevention, 39, 657-670. http://dx.doi.org/10.1016/j.aap.2006.10.012

[11] Findley, D.J., Hummer, J.E., Rasdorf, W., Zegeer, C.V. and Fowler, T.J. (2012) Modeling the Impacts of Spatial Relationships on Horizontal Curve Safety. Accident Analysis and Prevention, 45, 296-304. http://dx.doi.org/10.1016/j.aap.2011.07.018

[12] Council, F.M., Srinivasan, R., Masten, S., Carter, D. and Reurings, M. (2005) Development of a Speeding-Related Crash Typology: Summary Report. Federal Highway Administration, FHWA-HRT-10-039.

[13] NHTSA (2011) Traffic Safety Facts 2011 Data—Speeding. National Highway Traffic Safety Administration, DOT HS 811751.

[14] Jorgensen and Associates, Inc. (1978) NCHRP Report 197: Cost and Safety Effectiveness of Highway Design Elements. National Cooperative Highway Research Program, Washington DC.

[15] Hallmark, S., McDonald, T.J., Tian, Y. and Andersen, D. (2010) Safety Benefits of Paved Shoulders. Center for Transportation Research and Education, Iowa State University, Ames.

[16] Zador, P.L., Wright, P.H. and Karpf, R.S. (1982) Effect of Pavement Markers on Nighttime Crashes in Georgia. Insurance Institute for Highway Safety, Washington DC.

[17] Hammond, J.L. and Wegmann, F.J. (2001) Daytime Effects of Raised Pavement Markers on Horizontal Curves. ITE Journal, 71, 38-41.

[18] Bahar, G., Mollett, C., Persuad, B., Lyon, C., Smiley, A., Smahel, T. and McGee, H. (2004) NCHRP Report 518: Safety Evaluation of Raised Pavement Markers. National Cooperative Highway Research Program, Washington DC.

[19] Tsyganov, A.R., Machemehl, R.B. and Warrenchuk, N.M. (2005) Safety Impact of Edge Lines or Rural Two-Lane 
Highways. Center for Transportation Research, University of Texas at Austin, Austin.

[20] Potts, I.B., Harwood, D.W., Bokenkroger, C.D. and Hutton, J.M. (2008) Benefit-Cost Evaluation of MoDOT’s Total Striping and Delineation Program. Midwest Research Institute and the Missouri Department of Transportation, Kansas City.

[21] Hughes, W.E., McGee, H.W., Hussain, S. and Keegel, J. (1989) Field Evaluation of Edge Line Widths. Federal Highway Administration, Washington DC.

[22] Hall, J. (1987) Evaluation of Wide Edgelines. Transportation Research Record, 1114, 21-27.

[23] Cottrell, B.H., Lee, D., Molino, J. and Opiela, K.S. (2007) Can Pavement Marking Curve Delineation Improve the Consistency of Vehicle Speed and Lane Position? Results from a Nighttime Driving Experiment. Proceedings of the 2007 Annual Meeting of the Transportation Research Board, Washington DC, January 2007.

[24] Park, E., Carlson, P.J., Porter, R.J. and Anderson, C.K. (2012) Safety Effects of Wider Edge Lines on Rural Two-Lane Highways. Accident Analysis and Prevention, 48, 317-325. http://dx.doi.org/10.1016/j.aap.2012.01.028

[25] Chrysler, S.T. and Schrock, S.D. (2005) Field Evaluation and Driver Comprehension Studies of Horizontal Signing. Texas Transportation Institute, College Station.

[26] Retting, R.A. and Farmer, C.M. (1998) Use of Pavement Markings to Reduce Excessive Traffic Speeds on Hazardous Curves. ITE Journal, 68, 30-36.

[27] Hallmark, S., Hawkins, N. and Smadi, O. (2012) Evaluation of Low-Cost Treatments on Rural Two-Lane Curves. Center for Transportation Research and Education, Iowa State University, Ames.

[28] Vest, A., Stamatiadis, N., Clayton, A. and Pigman, J. (2005) Effect of Warning Signs on Curve Operating Speeds. Kentucky Transportation Center, Lexington.

[29] Molino, J.A., Katz, B.J., Hermosillo, M.B., Dagnall, E.E. and Kennedy, J.F. (2010) Simulator Evaluation of Low-Cost Safety Improvements on Rural Two-Lane Undivided Roads: Nighttime Delineation for Curves and Traffic Calming for Small Towns. U.S. Department of Transportation, Federal Highway Administration, Washington DC.

[30] FHWA (2011) Highways for LIFE Technology Partnership Program. Light Emitting Diode Raised Pavement Markers, Federal Highway Administration. www.fhwa.dot.gov/hfl/partnerships/safety_eval/led.cfm

[31] Torbic, D.J., Harwood, D., Gilmore, D.K., Pfefer, R., Neuman, T.R., Slack, K.L. and Hardy, K.K. (2004) NCHRP Report 500 Volume 7: A Guide for Reducing Collisions on Horizontal Curves. National Cooperative Highway Research Program, Washington DC.

[32] Griffin, L.I. and Reinhart, R.N. (1995) Patterns That Have Been Developed to Reduce Traffic Speeds and Crashes. AAA Foundation for Traffic Safety, Washington DC.

[33] Patel, R.B., Council, F.M. and Griffith, M.S. (2007) Estimating the Safety Benefits of Shoulder Rumble Strips on Two Lane Rural Highways in Minnesota: An Empirical Bayes Observational Before-After Study. 2007 TRB 86th Annual Meeting: Compendium of Papers CD-ROM, Washington DC, Vol. TRB\#07-1924.

[34] Bertini, R.L., Monsere, C., Nolan, C., Bosa, P. and Abou El-Seoud, T. (2006) Field Evaluation of the Myrtle Creek Advance Curve Warning System, SPR 352, FHWA-OR-RD-05_13. Portland State University, Portland.

[35] Tribbett, L., McGowen, P. and Mounce, J. (2000) An Evaluation of Dynamic Curve Warning Systems in the Sacramento River Canyon. Western Transportation Institute. www.coe.montana.edu/ce/patm/pubs/files/2000curve.pdf

[36] City of Bellevue Transportation Department (2009) Stationary Radar Sign Program 2009 Report. Bellevue.

[37] Mattox, J.H., Sarasua, W.A., Ogle, J.H., Eckenrode, R.T. and Dunning, A. (2007) Development and Evaluation of a Speed Activated Sign to Reduce Speeds in Work Zones. Proceedings of the 2007 Annual Meeting of the Transportation Research Board, Washington DC, January 2007.

[38] 3M (2006) A Before and After Study of 3M Driver Feedback Signs. Traffic Safety Systems, 3M United Kingdom PLC, Berkshire. www.morelock.co.uk/assets/3M/3M\%20DFS\%20field\%20study\%20results.pdf

[39] Winnett, M.A. and Wheeler, A.H. (2002) Vehicle Activated Signs—A Large Scale Evaluation. TRL548, Road Safety Division, Department for Transport, Wokingham, Berkshire.

[40] Santiago-Chaparra, K.R., Chitturi, M., Bill, A. and Noyce, D. (2012) Spatial Effectiveness of Speed Feedback Signs. Journal Transportation Research Record: Journal of the Transportation Research Board, 2281, 8-15. http://dx.doi.org/10.3141/2281-02

[41] FHWA (2009) Manual on Uniform Traffic Control Devices (MUTCD) for Streets and Highways. U.S. Department of Transportation, Federal Highway Administration, Washington DC.

[42] Hauer, E., Harwood, D.W., Council, F.M. and Griffith, M. (2002) Estimating Safety by the Empirical Bayes Method: A Tutorial. Journal Transportation Research Record: Journal of the Transportation Research Board, 1784, 126-131. http://dx.doi.org/10.3141/1784-16 
[43] Hovey, P.W. and Chowdhury, M. (2005) Development of Crash Reduction Factors. 14801(0) Ohio Department of Transport, Columbus.

[44] Persaud, B. and Lyon, C. (2007) Empirical Bayes Before-After Safety Studies: Lessons Learned from Two Decades of Experience and Future Directions. Accident Analysis and Prevention, 39, 546-555. http://dx.doi.org/10.1016/j.aap.2006.09.009

[45] Hauer, E. (1997) Observational Before-After Studies in Road Safety. Emerald Group Publishing Limited, Bingley.

[46] Carriquiry, A.L. and Pawlovich, M. (2004) From Empirical Bayes to Full Bayes: Methods for Analyzing Traffic Safety Data, White Paper. Iowa Department of Transportation, Ames, Iowa.

[47] Lan, B., Persaud, B., Lyon, C. and Bhim, R. (2009) Validation of a Full Bayes Methodology for Observational Before-After Road Safety Studies and Application to Evaluation of Rural Signal Conversions. Accident Analysis and Prevention, 41, 574-580. http://dx.doi.org/10.1016/j.aap.2009.02.010

[48] Congdon, P. (2001) Bayesian Statistical Modeling. John Wiley \& Sons Ltd., West Sussex.

[49] Persaud, B., Lord, D. and Palmisano, J. (2002) Calibration and Transferability of Accident Prediction Models for Urban Intersections. Journal Transportation Research Record: Journal of the Transportation Research Board, 1784, 5764. http://dx.doi.org/10.3141/1784-08

[50] Spiegelhalter, D., Thomas, A., Best, N. and Lunn, D. (2003) WinBUGS Version 1.4 User Manual. MRC Biostatistics Unit, Cambridge.

[51] Gamerman, D. (2006) Markov Chain Monte Carlo Stochastic Simulation for Bayesian Inference. Taylor \& Francis, Boca Raton.

[52] Gilks, W.R., Richardson, S. and Spiegelhalter, D.J. (1996) Markov Chain Monte Carlo in Practice. Chapman and Hall, London.

[53] Hallmark, S., Hawkins, N. and Smadi, O. (2013) Evaluation of Dynamic Speed Feedback Signs on Curves: A National Demonstration Project. Draft Final Report, FHWA Project DTFH61-07-H-00022. 
Scientific Research Publishing (SCIRP) is one of the largest Open Access journal publishers. It is currently publishing more than 200 open access, online, peer-reviewed journals covering a wide range of academic disciplines. SCIRP serves the worldwide academic communities and contributes to the progress and application of science with its publication.

Other selected journals from SCIRP are listed as below. Submit your manuscript to us via either submit@scirp.org or Online Submission Portal.
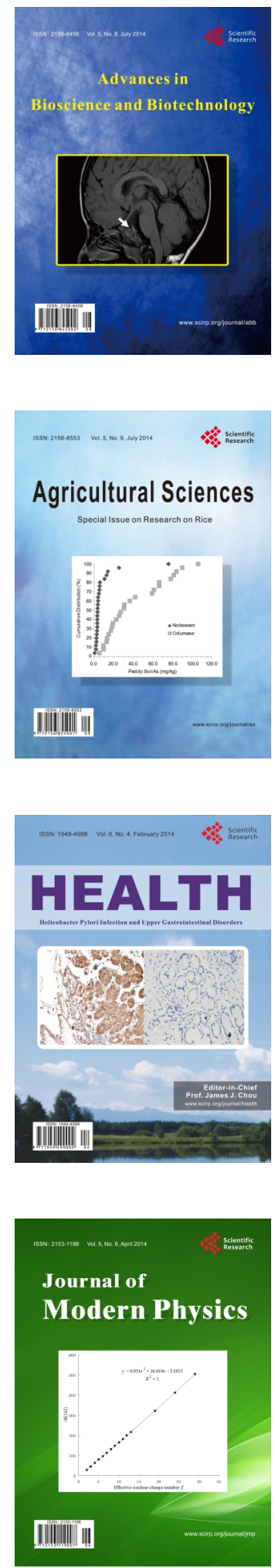
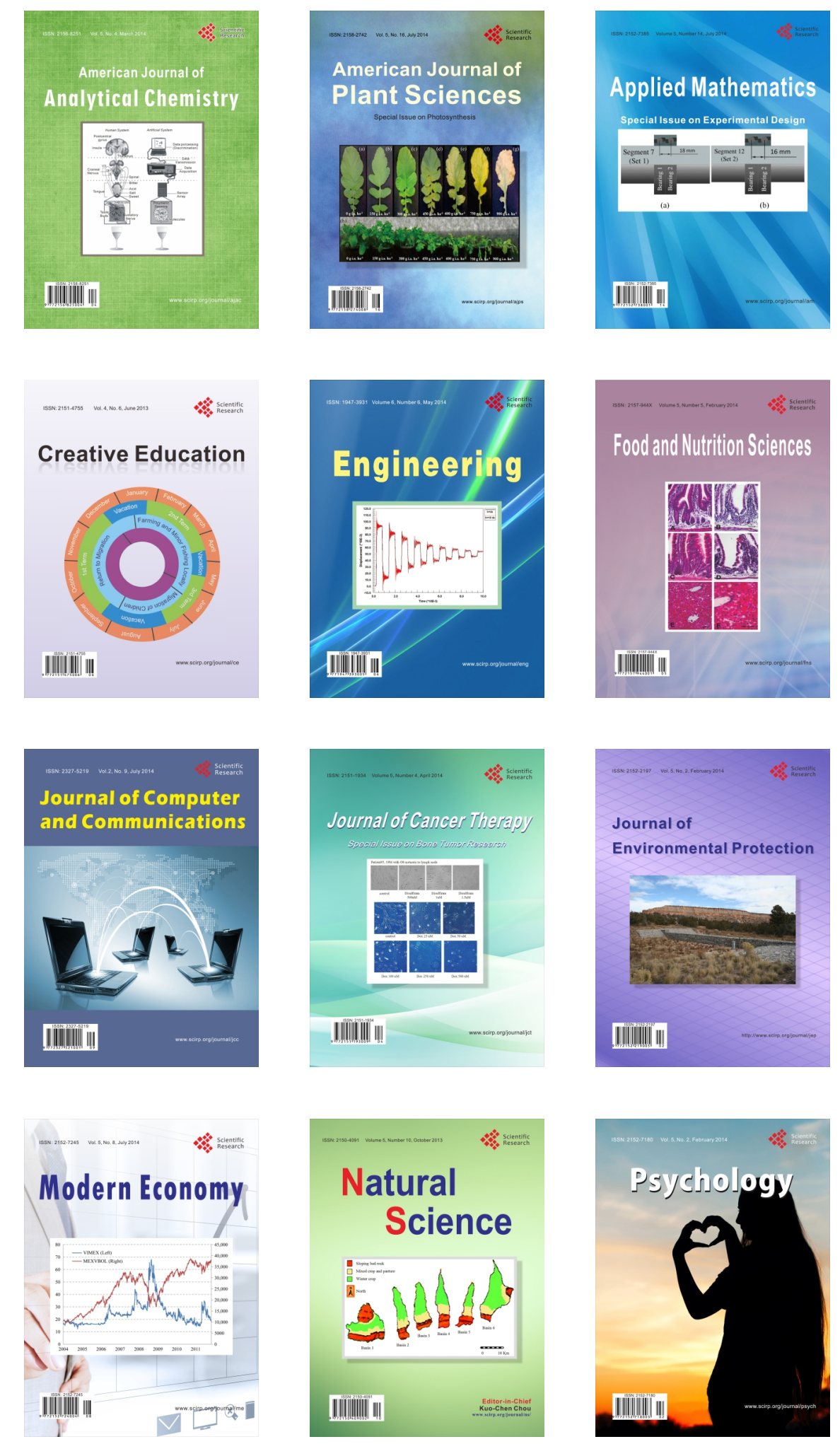